\title{
Reuna
}

\section{RECURSOS ESTRATÉGICOS: ESTUDO DE CASO EM HOTEL UPSCALE}

\section{STRATEGIC RESOURCES: CASE STUDY IN AN UPSCALE HOTEL}

http://dx.doi.org/10.21714/2179-8834/2020v25n1p20-34

\author{
Erick Pusch Wilke \\ Universidade Federal de Mato Grosso do Sul (UFMS), Brasil. \\ E-mail: erick.wilke@ufms.br \\ Luciana Correia Diettrich \\ Universidade Federal de Mato Grosso do Sul (UFMS), Brasil. \\ E-mail: luciana.diettrich@ufms.br
}

Submissão: 12 Out. 2019 Publicação: 4 Mai. 2020. Sistema de avaliação: Double blind review. Centro Universitário UNA, Belo Horizonte - MG, Brasil. Editor geral: Prof. Dr. Thiago Soares Nunes

Este artigo encontra-se disponível nos seguintes endereços eletrônicos:

http://revistas.una.br/index.php/reuna/article/view/1081

http://dx.doi.org/10.21714/2179-8834/2020v25n1p20-34

\section{Resumo}

A administração inadequada da base de recursos na hotelaria pode gerar a oferta de produtos e serviços desconexos com as demandas do público consumidor. Por outro lado, a configuração dos recursos de modo estratégico é capaz de gerar ao empreendimento ganhos significativos e vantagem competitiva. $O$ objetivo deste estudo foi identificar os recursos de natureza estratégica que estão associados ao desempenho superior de empreendimentos hoteleiros. Para tanto, realizou-se estudo de caso único no mercado hoteleiro, a partir do qual analisou-se o conteúdo dos comentários on-line postados por consumidores de serviços hoteleiros no site TripAdvisor. A amostra foi constituída por 691 comentários, postados entre 2015 e 2017. O conteúdo dos comentários foi submetido à análise netnográfica no software Iramuteq. Os resultados indicaram a existência de recursos centrais: o atendimento, o café da manhã, a limpeza e o ambiente. Concluiu-se que tais recursos e habilidades, ao serem reunidos, promoveram a criação de um valor único, capaz de gerar vantagem competitiva e desempenho superior.

Palavras-chave: Hotelaria; Recursos estratégicos; Estratégia; Comentários On-line.

\begin{abstract}
Inadequate management of the hotel resource base can lead to offering products and services disconnected from the requirements from guests' demands. On the other hand, the strategic configuration of resources can generate significant gains and competitive advantage. The purpose of this study was to identify the strategic resources associated with superior hotel performance. To this end, a unique case study was carried out in the hotel market, from which the content of online comments posted by hotel service consumers on the TripAdvisor website was analyzed. The sample consisted of 691 comments, posted between 2015 and 2017. The content of the comments was submitted to netnographic analysis in the Iramuteq software. The results indicate the existence of core resources: customer service, breakfast, cleaning


and the environment. We conclude that such resources and skills, when brought together, promoted the creation of a unique value capable of generating competitive advantage and superior performance.

Keywords: Hospitality; Strategic resources; Strategy; Online Comments.

\section{Introdução}

A segunda metade da década de 2010 foi especialmente difícil para a hotelaria brasileira, impactada por uma das mais duras e longas recessões econômicas de que se tem notícia. Segundo apontam os dados do relatório Hotelaria em Números da JLL Hotels \& Hospitality Group (2017), neste período houve queda em torno de 7\% na taxa de ocupação em todo o país, 1,6\% na diária média e 9\% no retorno por Apartamento Disponível (RevPar). O RevPar demonstra o estado de ociosidade dos apartamentos e é obtido pela multiplicação da taxa de ocupação pela diária média (BOEGER; YAMASHITA, 2006), trata-se, portanto, do principal índice hoteleiro.

A instabilidade do cenário político brasileiro influenciou a tomada de decisão dos investidores, de tal modo que em 2016 "[...] nenhuma importante transação hoteleira aconteceu no Brasil" (JLL HOTELS \& HOSPITALITY GROUP, 2017, p. 6), como aquisições ou fusões de grandes marcas ou empreendimentos hoteleiros.

Em meio a cenários de incerteza, como o mencionado acima, as empresas precisam ser ainda mais assertivas na tomada de decisão estratégica. A administração eficiente da base de recursos pode contribuir para que a empresa não somente sobreviva, mas obtenha desempenho superior frente aos concorrentes (BARNEY, 1991). Segundo apontam os pesquisadores, os recursos considerados estratégicos estão positivamente relacionados com o desempenho organizacional (CROOK et al., 2008; WINE; HAFEEZ, 2019). Isso significa que alocar os recursos disponíveis de modo intencional com a finalidade de compor novas ofertas ou agregar maior valor à oferta de produtos e serviços existentes é uma opção estratégica que pode trazer resultados altamente positivos.

Embora haja substantivo conhecimento produzido acerca da abordagem dos recursos nos domínios da estratégia, ainda há esclarecimentos que se fazem necessários sobretudo no campo da hotelaria. Assim, faz-se pertinente saber quais são os recursos associados ao bom desempenho hoteleiro, ainda mais quando a empresa enfrenta um cenário desfavorável e elevada concorrência.

Isto posto, o objetivo deste estudo esteve centrado em identificar os recursos de natureza estratégica que estão associados ao desempenho positivo de empreendimentos hoteleiros. Para tanto, escolheu-se aprofundar o estudo em um único empreendimento que ilustra o contexto em estudo. Segundo Claver-Cortés et al. (2007, p. 17), "estudar os hotéis localizados em um destino específico pode se mostrar relevante, uma vez que eles competem para conseguir recursos e clientes similares". Trata-se de um hotel de categoria superior, localizado em uma das capitais do Centro-Oeste brasileiro, inaugurado no ano de 2014. Nos anos seguintes, mesmo em meio à recessão econômica a qual provocou queda acentuada nos principais índices de desempenho da hotelaria urbana em todo o Brasil, o empreendimento apresentou desempenho favorável e elevados índices de satisfação, conquistando prêmios de excelência como Loved By Guests Most Wanted Award, Guest Review Awards e Traveler's Choice.

REUNA, Belo Horizonte - MG, Brasil, v. 25, n. I, p. 20-34, Jan. - Mar. 2020 - ISSN 2179-8834 
Este estudo e resultados foram construídos a partir da visão do principal consumidor dos produtos e serviços hoteleiros, o hóspede. Para tanto, extraiu-se e analisou-se o conteúdo dos comentários on-line postados no site TripAdvisor. $\mathrm{Na}$ atualidade, esse método tem sido amplamente utilizado em vários estudos no âmbito da hotelaria, seja para melhor compreender o comportamento e as intenções de compra do consumidor (SPARKS et al., 2016), seja para aprimorar a gestão interna da empresa (NGUYEN; COUDOUNARIS, 2015). Na era da tecnologia mobile, os consumidores expõem suas opiniões em tempo real. Isso tem exigido das empresas respostas imediatas não apenas para minimizar o efeito negativo de determinado comentário ou avaliação, mas um (re)pensar da estrutura dos recursos e capacidades organizacionais (CANTALLOPS; SALVI, 2014; HU; CHEN, 2016). Neste sentido, a presente pesquisa acompanha os estudos contemporâneos no campo da administração hoteleira.

Sendo assim, acredita-se que os resultados aqui apresentados possam contribuir para que as empresas hoteleiras prestem serviços de melhor qualidade, em consonância com as mais elevadas expectativas do consumidor. Ainda, os resultados poderão subsidiar a tomada de decisão em direção ao aprimoramento da oferta de valor por meio da administração eficiente da base de recursos. Além disso, empreendimentos hoteleiros em uma categoria inferior poderão reconhecer os recursos com maior capacidade de promover retornos positivos e ampliar sua oferta de valor, fazendo com que os clientes não apenas sintam-se satisfeitos, mas surpreendidos positivamente, superando as expectativas iniciais

\section{Fundamentação teórica}

Uma organização pode ser considerada um conjunto de recursos. A partir dessa visão, os recursos organizacionais assumem o ponto central da estratégia empresarial.

"Recurso" é um termo geral utilizado para designar os inputs do processo organizacional (CROOK et al., 2008). São ativos, capacidades e processos controlados pela organização os quais permitem que ela conceba e implemente suas estratégias de modo eficiente e eficaz. Por sua vez, o chamado "recurso estratégico" é conhecido segundo sua capacidade de prover vantagem competitiva sustentável. Ele responde a quatro critérios devendo ser valioso(1), de tal forma que reduza os custos ou aumente o valor para os clientes, raro(2) o suficiente para que os concorrentes não utilizem o mesmo recurso para competir com o valor, e difícil de imitar(3) ou substituir(4), o que impede que os concorrentes ganhem paridade (BARNEY, 1991). Esse conjunto de características estabelece uma base sólida para que a empresa obtenha resultados positivos frente aos demais concorrentes.

Os resultados positivos são gerados a partir dos produtos e serviços que são realmente importantes para o consumidor (MAHONEY; PANDIAN, 1992). No âmbito da arena concorrencial, a geração de valor superior ocorre quando a empresa excede a habilidade de seus competidores em prover soluções para as necessidades de seus consumidores (SIRMON et al., 2007). Nesse contexto, a empresa necessita de um repertório superlativo de recursos e ainda, habilidade para obter, acumular, explorar, combinar e liberar recursos com a finalidade de gerar valor e obter vantagem competitiva. 
Essa vantagem advém das imperfeições de mercado, de uma condição de heterogeneidade segundo a qual as organizações possuem diferentes conjuntos de recursos (PETERAF, 1993). Neste sentido, a posse de recursos pode ser associada à geração de vantagem competitiva. Sendo estes recursos qualificados como de alto valor, raros, difíceis de imitar e substituir, podem não apenas gerar vantagem competitiva, mas permitir sustentá-la ao longo do tempo.

Recursos de alto valor apresentam características singulares. Um recurso estratégico pode ter origem em variáveis pouco conhecidas, primeiro porque a relação entre o recurso e a vantagem que ele proporciona pode ser pouco compreendida em sua totalidade e segundo porque ele pode estar sustentado em uma relação social complexa, como o relacionamento entre gestores, a cultura organizacional ou a reputação com fornecedores e com clientes. Essa situação estabelece uma barreira a qual dificulta que as empresas concorrentes implementem as mesmas estratégias, mesmo quando de posse de recursos similares (BARNEY, 1991).

Ao considerar a estratégia como a constante busca por resultados favoráveis para o negócio - ou seja, obtenção de retornos acima do normal - é razoável admitir que alguns recursos contribuem de modo significativo para alcançar esse objetivo mais do que outros. Sendo a natureza dos recursos tangíveis (ex. equipamentos, objetos, máquinas, estrutura) e intangíveis (ex. habilidades, rotinas, processos, conhecimento, informações e atendimento), uma combinação entre eles pode gerar algo substancialmente novo. Os recursos controlados por uma empresa podem gerar algo que é maior do que a soma individual desses recursos, gerando um recurso novo, complexo, interdependente e difícil de ser imitado. Segundo Kluyver e Pearce II (2010, p.8), significa que "as diferentes atividades encaixam-se e reforçam umas às outras para criar valor econômico real". Significa não somente possuir os melhores recursos, mas envolve a competência distintiva de fazer o melhor uso deles (PENROSE, 1959). Neste sentido, a habilidade da organização em coordenar os esforços humanos e a alocação eficiente de seus recursos são essenciais para gerar ofertas de maior valor.

Portanto, ao considerar a empresa um conjunto de recursos tangíveis e intangíveis, assume posição prevalente a administração eficiente da base de recursos. Ao adquirir, explorar e combinar recursos e capacidades, a empresa pode proporcionar aos consumidores soluções únicas de elevado valor de mercado e assim, obter vantagem frente à concorrência.

A indústria hoteleira é um mercado altamente competitivo. No Brasil, são poucos os mercados onde as taxas de ocupação permitem uma margem de tranquilidade para a operação diária. Essa não é realidade da grande maioria dos hotéis brasileiros. Para se ter uma noção, segundo dados do Fórum de Operadores Hoteleiros no Brasil, a taxa de ocupação média dos hotéis brasileiros no período entre 2010 e 2014 esteve em torno de $63 \%$ e a partir de 2015 houve queda de mais de 8 pontos percentuais (INFOHB, 2018). Com isso, os principais objetivos dos administradores se concentram em aumentar a taxa de ocupação das unidades habitacionais enquanto elevam as receitas médias das diárias, dos alimentos e bebidas e dos eventos. Chamar a atenção do cliente e influenciar na decisão de compra é um desafio cotidiano.

Os comentários postados por hóspedes são uma grande fonte de influência para o comportamento do consumidor na atualidade e têm impactado até mesmo o desempenho dos hotéis (TUOMINEN, 2011; ZHANG; YANG, 2019). Gerenciar a 
(in)satisfação dos consumidores por meio dos canais de comunicação on-line passou a ser uma função essencial dentro da estrutura de relacionamento com os clientes. Cada vez mais hotéis estão despertando para a importância da gestão da reputação on-line (ZHANG; VÁSQUEZ, 2014). Por meio dos comentários, os hóspedes habitualmente destacam os elementos que de forma positiva ou negativa afetaram a experiência da estadia durante o período de hospedagem. Para os hóspedes, são itens que merecem elogios ou reclamações. Para a administração estratégica, são recursos e capacidades com elevado valor informacional. Conforme atesta Singh et al. (2018), o boca a boca on-line é uma poderosa estratégia de marketing.

Estudos sobre o campo da hotelaria têm identificado uma série de recursos. Alguns deles promoveram o agrupamento em subcategorias, como Qu, Ryan e Chu (2000), os quais analisaram 28 fatores divididos em 6 categorias e Shanka e Taylor (2004), que contabilizaram 18 fatores em 3 categorias. Outras pesquisas analisaram a influência de cada recurso individualmente, como Callan e Bowman (2000) estimando 38 recursos e Rhee e Yang (2015) com apenas 5 fatores.

O fato é que esses estudos têm identificado a preeminência de alguns recursos sobre outros, cujos resultados os relacionam tanto às preferências dos hóspedes quanto ao bom desempenho do empreendimento. Segundo os resultados de Callan e Bowman (2000), os hóspedes acima de 50 anos de idade dão maior importância à limpeza, em segundo lugar ao valor do investimento, seguido pelo conforto da cama e cortesia do pessoal. No entanto, para a escolha do hotel pela primeira vez, esse público atribui maior importância ao valor do investimento, à segurança e seguridade e à localização, respectivamente.

No estudo de Shanka e Taylor (2004) os hóspedes em hotéis de 3 estrelas classificam a importância dos atributos do hotel em instalações físicas, serviços experimentados e serviços prestados. Qu, Ryan e Chu (2000) identificaram que a qualidade do desempenho da equipe é o atributo que mais está associado à satisfação dos hóspedes, seguido pela qualidade das facilidades no quarto, valor do investimento e variedade e eficiência dos serviços, nesta ordem. Ainda segundo os resultados encontrados por Rhee e Yang (2015), há forte interesse dos hóspedes pelas características de conforto do quarto e pelo valor do investimento, mas a limpeza foi referenciada como um dos requisitos fundamentais para todos os tipos de negócios na hotelaria. Cada um desses recursos está sensível à avaliação pelo hóspede que em determinado momento da estadia pode se manifestar com maior intensidade, sendo, portanto, objetivo de satisfação ou insatisfação.

Sobre os hotéis upscale - também conhecidos como hotéis de luxo ou superior - é importante mencionar que se caracterizam por proporcionar mais conforto e requinte aos usuários, ofertam serviços diferenciados, amplas instalações e atendimento personalizado.

Conforme os estudos mencionados, os hóspedes destinam grande atenção em suas avaliações para dois tipos de recursos, os humanos e os físicos. O primeiro diz respeito ao esforço da atividade humana, exposto por meio do atendimento e da prestação de serviços. De fato, a hotelaria é um setor altamente caracterizado e baseado nas competências pessoais e no exercício cotidiano das habilidades dos indivíduos. Segundo Antoncic e Antoncic (2011), especialmente na hotelaria "a qualidade dos funcionários, suas competências, lealdade e comprometimento são extremamente importantes para o desempenho do negócio". 
Por sua vez, os recursos físicos atuam como formas complementares e igualmente relevantes para o bom desempenho do produto hoteleiro, incluindo design, decoração, limpeza, facilidades, comodidades e cama confortável, por exemplo. Conforme afirmam Ren et al. (2016), as interações com elementos humanos ou físicos são importantes para moldar a experiência do cliente, refletindo diretamente nos índices de satisfação dos hóspedes.

Sendo assim, a gestão estratégica e o alinhamento inteligente dos recursos de maneira a proporcionar entre si uma complementariedade única pode promover novas atividades e experiências de alto valor. Smith e Wheeler (2002) afirmam que o gerenciamento adequado da experiência do cliente pode transformar os clientes em defensores, sobre os quais a vantagem competitiva e a lucratividade a longo prazo podem ser alcançadas.

\section{Metodologia}

O estudo foi realizado tendo como base de pesquisa um hotel de categoria superior localizado em uma capital do Centro-Oeste brasileiro. A escolha do referido hotel se deu em razão de seu bom desempenho mesmo durante o período de incertezas ambientais. O empreendimento recebeu diversas premiações em âmbito nacional e internacional desde sua inauguração.

Os dados foram coletados por meio do site TripAdvisor (o TripAdvisor é o maior site de viagens do mundo, com mais de 630 milhões de avaliações sobre aproximadamente 7,5 milhões de acomodações, restaurantes, companhias aéreas e experiências de turismo e consumo). Tais dados, quais sejam, comentários individuais e livres usualmente indicando aspectos positivos ou negativos da experiência vivenciada no empreendimento hoteleiro abrangeram desde 2014 , ano que marcou a inauguração do hotel, até 2017.

O universo da pesquisa foi identificado em mais de 1,5 mil comentários. $O$ procedimento de seleção da amostra compreendeu a coleta com os seguintes passos: da lista exposta nas páginas pares foram extraídos o primeiro, o terceiro, o quinto comentários, e assim sucessivamente. Nas páginas ímpares, foram extraídos o segundo, quarto e sexto comentários, e assim sucessivamente. A amostra final resultou em 691 comentários.

Para a análise dos dados, foi utilizado o software Iramuteq 3.5.1. Antes, porém, procedeu-se à limpeza e ajuste da base de dados, corrigindo as palavras escritas incorretamente (ex. "utiluzar" para "utilizar") e uniformizando termos (ex. "check in" para "check-in"). O Iramuteq é um software gratuito alicerçado no software estatístico $R$, e permite a realização de análises gerais de textos. Em suma, o Iramuteq é capaz de trazer informações lexográficas, incluindo estatísticas básicas (como frequência de palavras) e avançadas (como análise fatorial).

Ao iniciar o processo de tratamento dos dados, foi permitido que as categorias emergissem à medida que o conteúdo dos comentários era examinado. Esse procedimento permitiu emergir aqueles elementos não previstos anteriormente pelos pesquisadores, o que enriqueceu a análise dos dados.

Para analisar os dados, realizou-se a análise de similitude, nuvem de palavras e classificação hierárquica descendente (CHD). A análise de similitude apresenta por meio de uma imagem as conexões existentes entre as palavras do corpus textual e 
então, é possível inferir a estrutura de construção do texto e os temas a ele relacionados. A nuvem de palavras permite visualizar o grau de frequência das palavras no corpus textual, de modo que as mais frequentes apresentam-se mais chamativas. Finalmente, com a CHD é possível analisar a correlação entre os textos e seus vocábulos e então inerir sobre o conteúdo do corpus e compreender os discursos e ideias.

\section{Resultados}

A amostra, constituída por 691 comentários, resultou em 888 segmentos de textos. Emergiram 29.953 ocorrências (palavras, vocábulos ou formas), sendo 3.420 palavras distintas e 1.790 com uma única ocorrência.

O processamento dos dados no software Iramuteq gerou o primeiro output a ser analisado, a nuvem de palavras (figura 1). O tamanho do corpus textual, ou seja, a quantidade de palavras sob análise, permitiu a exclusão de alguns termos que apresentaram pouca ou nenhuma significância como "hotel", "ficar", "equipa" e aquelas com frequência inferior a 50 ocorrências. Essa medida foi fundamental para tornar a nuvem visualmente compreensível.

Ao observar a nuvem de palavras alguns termos merecem consideração. De forma equivalente, os termos "excelente", "bom" e "café da manhã" foram recorrentes na fala dos hóspedes e assumiram posição de destaque. Em segundo plano, não menos importante, é possível perceber o termo "ótimo", "atendimento" e na sequência "Campo Grande", "confortável", "qualidade", "melhor", "novo", "restaurante", "funcionário", "recomendar" e "serviço".

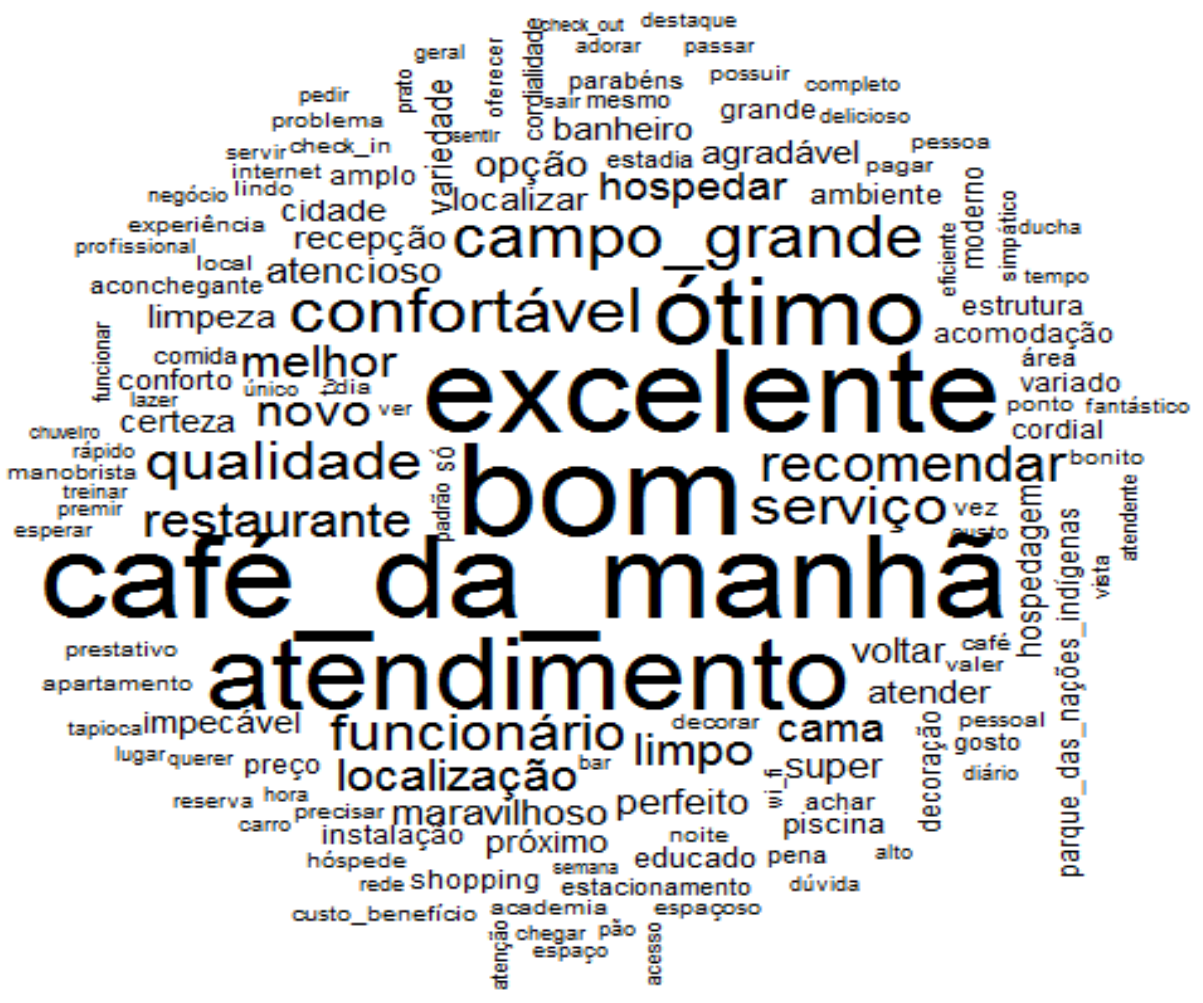

Figura 1 - Nuvem de palavras

Fonte: dados da pesquisa.

REUNA, Belo Horizonte - MG, Brasil, v. 25, n. I, p. 20-34, Jan. - Mar. 2020 - ISSN 2179-8834 
Os termos em primeira evidência são formados essencialmente por elogios. Os hóspedes associaram seus comentários com palavras positivas, de modo que a percepção geral do hotel ou de algum item em especial mereceu um elogio. Ainda neste grupo de ocorrências o "café da manhã" se destacou. A imagem percebida pelo hóspede sobre as características do hotel está associada especialmente a este item (402 ocorrências. Doravante, o texto apresentará entre parênteses a contagem de frequência do corpus textual).

Quanto aos termos em segunda evidência, encontra-se em destaque o "atendimento" (337). Nesta direção, foram mencionados outros termos que remetem ao atendimento como "qualidade", "melhor", "funcionário" e "serviço". São palavras que reforçam a percepção dos hóspedes enfatizando um lugar de destaque para a prestação de serviços do hotel. Ainda, alguns termos apareceram discretamente com menor quantidade de citações em relação aos já mencionados. Chama a atenção a ocorrência significativa dos termos "limpo" e "cama".

A análise de similitude contribuiu para identificar as palavras correlacionadas, ou seja, termos que foram escritos conjuntamente e o grau de aproximação entre ambos e entre os clusters decorrentes (quanto mais espessa a linha de conexão, maior é a proximidade).

O diagrama de similitude (figura 2) apresenta um eixo de relacionamento com elevado grau de correlação entre o "atendimento", "excelente", "café da manhã" e "bom". Uma análise de cada um destes itens revela aspectos interessantes. No cluster "atendimento" existe uma forte ligação com os termos "cordialidade", "conforto", "hospedagem", "limpeza", "check-in" e "check-out". Esse cluster expressa a visão mental do hóspede e os itens que ele associa ao aspecto gerador do atendimento. Neste caso, a experiência do atendimento foi altamente positiva, estando fortemente relacionada ao termo "excelente", evidenciado por meio da "cordialidade" e ainda na "rapidez" na prestação de serviços. No outro cluster, alguns aspectos estão diretamente ligados ao adjetivo "excelente". Para o hóspede, a "localização" e o "acesso" são fundamentais para atender ao público interessado em "negócios". Foi compreendido que os hóspedes, mesmo com foco na realização de negócios durante a estadia, valorizam a proximidade do hotel com centros de lazer e facilidades, como o Parque das Nações Indígenas (54) e o shopping (48). 


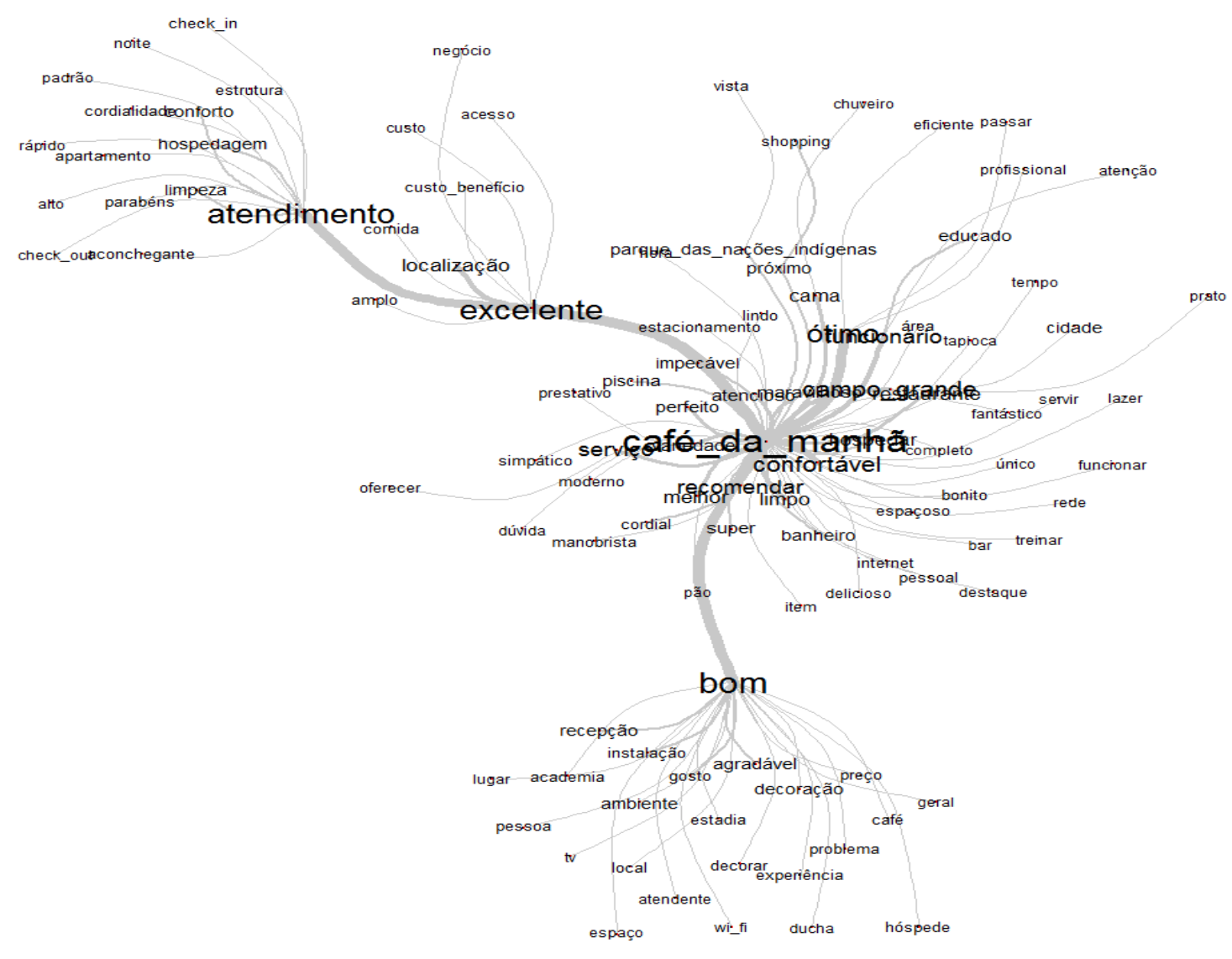

Figura 2 - Diagrama de similitude

Fonte: dados da pesquisa.

Na sequência, observou-se uma densa nuvem de palavras ao redor de "caféda-manhã". Dentre as mais citadas pode-se destacar "ótimo", "Campo Grande", "funcionário", "recomendar", "melhor". $\mathrm{Na}$ avaliação geral deste conglomerado é possível inferir que o hóspede tem no café da manhã um recurso essencial que contribui significativamente para a avaliação positiva da experiência de hospedagem. Oriundos desta percepção observam-se desdobramentos comportamentais como a iniciativa do hóspede em recomendar, pois para ele trata-se do melhor produto desta natureza em Campo Grande, aliado ao ótimo atendimento prestado pelos funcionários.

Finalmente, em conexão com o adjetivo "bom" estão termos relacionados aos aspectos físicos do hotel e, ainda, menção a algum "problema". Vale destacar que os hóspedes destinaram especial atenção aos detalhes da decoração (52). O ambiente agradável (74) e as instalações (52) contribuíram para uma percepção positiva da "estadia" e da "experiência". A fim de identificar as razões que levaram os hóspedes a citar "problema" (36), os comentários foram analisados individualmente. Em sua maioria, dizem respeito a comentários como "não tive nenhum problema" ou "sem problemas". Outros comentários, no entanto, fazem referências a inconsistências encontradas pelos hóspedes no momento do fechamento da diária, pagamento e/ou relacionadas aos dados da reserva. 
O corpus textual ficou dividido em duas categorias, subdivididas em duas classes cada uma (Figura 3). A classe 4 apresenta grande ênfase sobre a localização do hotel, indicando que esse elemento tem agradado aos hóspedes. Segundo eles, a proximidade com o shopping e o principal parque da cidade é altamente positiva e, embora não represente fonte tão satisfatória quanto os elementos internos do hotel, é merecedora de elogios de forma a posicionar o hotel como o melhor disponível na cidade.

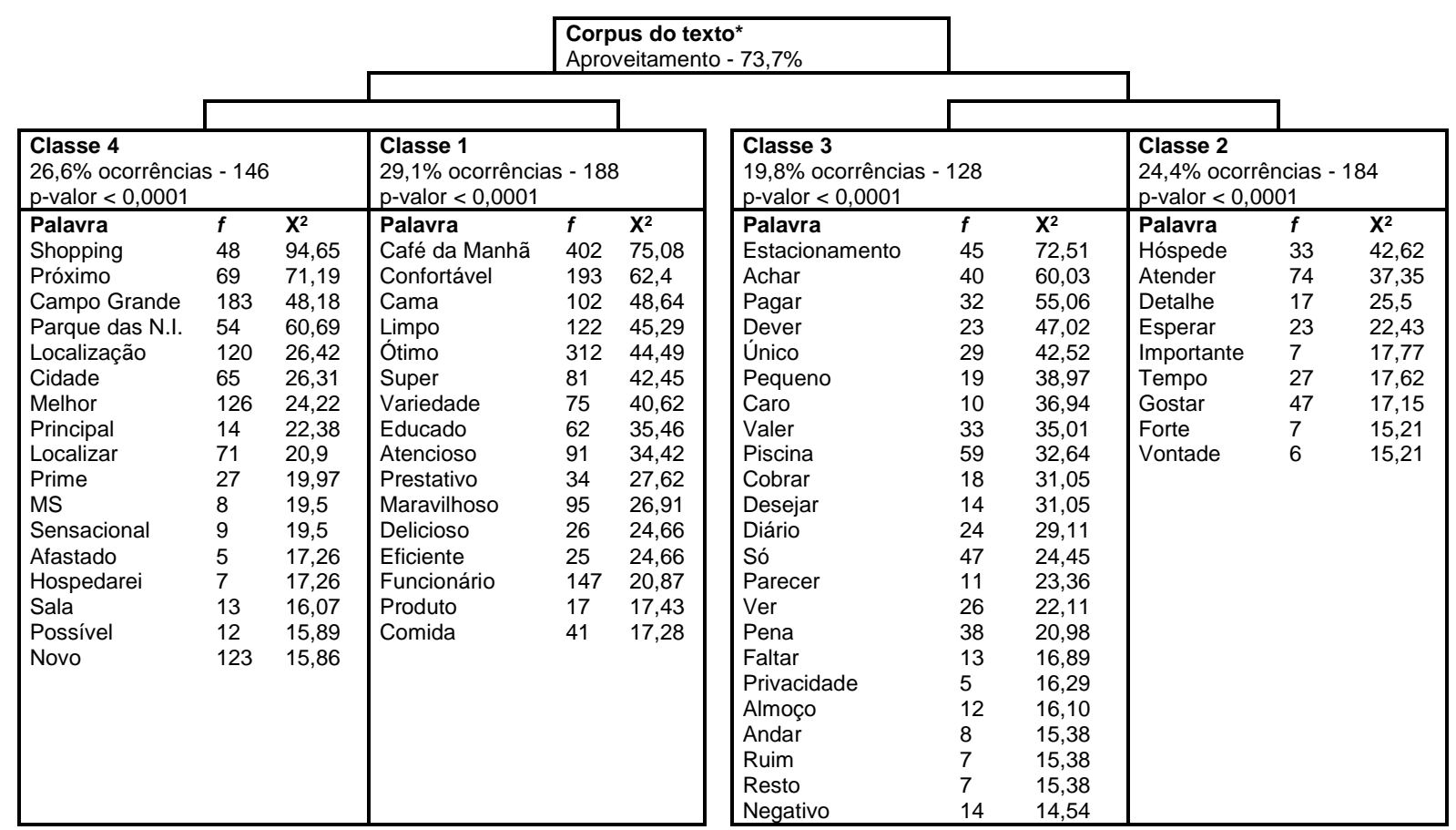

*Foram mantidos no gráfico apenas os termos que apresentaram alta significância $(\alpha<0,01)$ e qui-quadrado superior a 3,80 $\left(X^{2}\right)$.

Figura 3 - Organograma das classes.

Fonte: dados da pesquisa.

A classe 1 reúne o maior agrupamento de palavras, $29,1 \%$ do total. Ela contém os elementos de maior expressão positiva encontrada no corpus textual. É possível destacar novamente a presença significativa do "café da manhã" e o destaque para a variedade (75) de itens do cardápio. Na sequência foram apontados itens relacionados ao bem-estar do hóspede, como o conforto, a cama e limpeza. Notadamente esses itens estão associados a elogios como ótimo, maravilhoso, delicioso, eficiente.

A classe 3 contém $19,8 \%$ do total de ocorrências e apresenta a menor correlação com as demais classes. Esse distanciamento é compreensível, uma vez que o grupo é composto por termos que representam os aspectos negativos mencionados pelos hóspedes, dentre eles 0 estacionamento citado em 45 comentários, sendo 3 elogios (ex. "excelente estacionamento com manobrista"), 4 informativos (ex. "estacionamento pago com manobrista 24h") e 38 reclamações quanto à cobrança do serviço (ex. "estacionamento cobrado desnecessário para este tipo de hotel"). Outra fonte de manifestações foi a "piscina" e sua área de banho, contabilizando 59 comentários em sua maioria desfavoráveis. As manifestações se referem ao tamanho da piscina (ex. "minúscula"), sua localização (ex. "é muito exposta 
para a recepção tirando a liberdade dos hóspedes"). Elogios também foram relatados (ex. "limpa e agradável", "piscina e restaurante fantásticos").

A classe 2 é a segunda maior, com $24,4 \%$ das ocorrências. Esse agrupamento expressa a relação estabelecida entre o cliente e a empresa. Notadamente, estão descritos fatores considerados relevantes no tratamento da empresa para com 0 hóspede. Segundo a visão dos hóspedes, a atenção aos detalhes, a vontade dos colaboradores, o tempo gasto, a agilidade no atendimento e a iniciativa em atender as solicitações são elementos importantes para o sucesso da relação.

\section{Discussão}

Neste estudo buscou-se identificar os recursos associados ao bom desempenho na hotelaria, segundo a visão do hóspede. Os resultados posicionam três recursos no centro estratégico da empresa: o café da manhã, o atendimento e o ambiente. Tais resultados foram possíveis a partir da análise de um caso único e significativo, o qual possibilitou extrair algumas observações teóricas e gerenciais apresentadas a seguir.

O café da manhã assumiu a primazia dentre todos os recursos associados aos apontamentos de satisfação. Essa informação chama a atenção, uma vez que se trata de um recurso supostamente trivial amplamente utilizado pela indústria hoteleira. $A$ princípio, é razoável supor que ele possa ser facilmente copiado. No entanto, o resultado corrobora os achados de Espino-Rodríguez e Padrón-Robaina (2005), os quais posicionaram a cozinha, o restaurante e o bar como atividades centrais estratégicas na hotelaria. $\mathrm{O}$ café da manhã congregou recursos de alto valor (humanos e físicos), raros na medida em que ao ser aplicado domínio do conhecimento e habilidades específicas, resultou em excelente atendimento e variedade de produtos disponíveis aos hóspedes. Esse recurso sinérgico não apenas atendeu as expectativas dos hóspedes, mas também seus desejos, a ponto de surpreendê-los.

O atendimento tem sido compreendido como um dos grandes desafios na indústria hoteleira, na qual a prestação de serviços depende em grande medida dos esforços e da iniciativa de indivíduos que estabelecem contato direto e pessoal com o cliente, sendo corresponsáveis pelo seu bem-estar e satisfação durante todo o período de hospedagem. Segundo a visão do hóspede, dois momentos são representativos do atendimento prestado pelo hotel: o check-in e o check-out. De fato, eles podem ser compreendidos como uma fonte geradora de expectativa na relação empresa-cliente. Ao chegar ao hotel o cliente inicia a avaliação in loco imediatamente nos primeiros passos e atribui ao processo de entrada na recepção grande parte da responsabilidade pela boa acolhida e hospitalidade. De modo semelhante, o processo de saída encerra a experiência da "hospedagem" e o hóspede não deseja lidar com surpresas desagradáveis, como cobranças indevidas. Tem-se, portanto, um conglomerado que unifica um recurso de natureza física e outro de natureza humana em uma oferta singular de alto valor. Tais achados estão em conformidade com os apontamentos de Shanka e Taylor (2014) quando identificaram que a satisfação do hóspede está diretamente associada em primeiro lugar ao atendimento do front office, especialmente a eficiência do check-in e check-out.

Os recursos associados ao ambiente receberam muitas observações. Significa que os hóspedes estão atentos aos detalhes do ambiente como a limpeza, decoração, 
barulho e tamanho dos cômodos. Esse resultado se aproxima dos achados de Ren et al. (2016), quando posicionam esses elementos, chamados de "experiência tangívelsensorial", diretamente relacionados com a satisfação do hóspede. Neste ponto concordamos, mas os referidos recursos não assumiram a primazia em nosso estudo, atuando à margem dos recursos centrais.

Sobre esse aspecto, nossos resultados também chamam a atenção para a necessidade de gestão integrada dos recursos marginais, os quais orbitam os recursos estratégicos, podendo contribuir ou não para a experiência da hospedagem. Nesta relação, os aspectos considerados negativos na avaliação dos hóspedes, como a localização da piscina ou a cobrança do estacionamento, representaram quase 1/5 dos comentários. Esse aspecto enfatiza que a administração hoteleira deve estar atenta ao nível dos detalhes, buscando mitigar o efeito negativo ocasionado por itens que são percebidos em dissonância da oferta de valor.

Nessa direção, a oferta de produtos únicos deve ser prioridade. Os resultados aqui apresentados salientam a relevância da oferta de produtos de elevado valor para o consumidor, baseados na sinergia entre os recursos disponíveis. Neste sentido, a hotelaria deve atentar para dois aspectos essenciais: qualificação dos recursos e conexão entre eles.

A qualificação deve ser direcionada para substanciar valor ao recurso, extraindo dele seu maior potencial em favor da estratégia organizacional. Exemplos desses recursos foram evidenciados em nossos dados e se fazem presentes no hotel estudado. A recorrente citação como o melhor local para se hospedar em Campo Grande e a eficiência, educação e prestatividade dos funcionários representam o tipo de recurso que para a concorrência é difícil de imitar, possui baixa probabilidade de ser substituído e raro em sua disponibilidade (BARNEY, 1991). Em consonância com Callan e Bowman (2000), reforçamos que a atitude e o comportamento dos funcionários são componentes essenciais para a percepção da qualidade dos serviços. Por sua vez, a conexão atua como propulsora da sinergia e encadeamento dos serviços prestados, por meio da qual o hóspede recebe uma proposta de valor integrada. Em nossos achados identificamos a oportunidade de encadeamentos a partir dos recursos mais citados podendo resultar em conexões únicas como, por exemplo, conectar a boa "localização" com a excelência do "atendimento" reduzindo o efeito da percepção negativa a respeito do "estacionamento". Trata-se, assim como referenda Rhee e Yang (2015), do esforço dos gerentes em escolher a utilização dos recursos mais eficientes em detrimentos de outros.

O desempenho superior obtido pelo empreendimento hoteleiro estudado, mesmo em face de um cenário desfavorável, pode elucidar oportunidades para a gestão de hotéis de categorias inferiores. Consoante Fraj et al. (2015), hotéis com classificação mais alta normalmente oferecem oportunidades para inovar. No entanto, a inovação não é exclusiva da hotelaria upscale. Os resultados indicam que a inovação pode manifestar-se poderosamente por meio de ações de interrelacionamento entre esses recursos. A ideia é gerar algo maior do que a soma de suas partes e, portanto, surpreendentemente valioso, raro, difícil de imitar ou substituir.

Finalmente, ao compreender com profundidade a atuação e alcance dos recursos hoteleiros, bem como seu comportamento e suas limitações, é possível extrair da base disponível algumas opções de natureza estratégica altamente 
vantajosas. Competitivamente, como ressaltaram Tavitiyaman, Qu e Zhang (2011), a garantia da satisfação e a crescente lealdade do cliente, o hotel não deverá preocuparse com os concorrentes.

\section{Considerações finais}

Este estudo analisou os recursos hoteleiros a partir da visão baseada em recursos. A intenção foi acessar os recursos considerados estratégicos para a obtenção de performance superior. Embora os recursos organizacionais tenham sido extensivamente abordados pelos pesquisadores, poucos deles se apontaram com claridade e discutiram seus efeitos em um setor considerado crucial para a economia do turismo. Nossos resultados mostram que, na hotelaria, dominar os recursos centrais e periféricos é essencial.

Embora tenha proporcionado contribuições consistentes, é possível reconhecer limitações. Uma delas se refere a generalização das conclusões. A indústria da hotelaria é composta por empreendimentos com diversas características, categorias e níveis de serviço, o que dificulta a amplificação dos resultados. Seria interessante realizar estudo semelhante em diferentes composições hoteleiras, de modo a possibilitar comparações com os achados aqui expostos.

\section{Referências}

ANTONCIC, J.; ANTONCIC, B. Employee loyalty and its impact on firm growth. International Journal of Management \& Information Systems, v.15, n.1, p. 81-87, 2011.

BARNEY, J. Firm Resources and Sustained Competitive Advantage. Journal of Management. V.17, n.1, p.99-120, 1991.

BOEGER, M. A.; YAMASHITA, A. P. Gestão financeira para meios de hospedagem: hotéis, pousadas, hotelaria hospitalar e a hospitalidade. 1. ed. 2. reimpr. São Paulo: Atlas, 2006.

CALLAN, R. J.; BOWMAN, L. Selecting a hotel and determining salient quality attributes: A preliminary study of mature British travellers. International Journal of Tourism Research, v. 2, n. 2, p. 97-118, 2000.

CANTALLOPS, A. S.; SALVI, F. New consumer behavior: a review of research on eWOM and hotels. International Journal of Hospitality Management, v. 36, p.41$51,2014$.

CLAVER-CORTÉS, E.; MOLINA-AZORÍN, J.; PEREIRA-MOLINER, J. The impact of strategic behaviours on hotel performance. International Journal of Contemporary Hospitality Management, v. 19, n. 1, p. 6-20, 2007.

CROOK, T.; KETCHEN JR., D.; COMBS, J.; TODD, S. Strategic resources and performance: a meta-analysis. Strategic Management Journal, v. 29, n. 11, p. 11411154, 2008. 
ESPINO-RODRÍGUEZ, T.; PADRÓN-ROBAINA, V. A resource-based view of outsourcing and its implications for organizational performance in the hotel sector. Tourism Management, v. 26, n. 5, p. 707-721, 2005.

FORUM DE OPERADORES HOTELEIROS DO BRASIL (2018). InFONB. Ed. 134. Disponível em: <http://fohb.com.br/wp-content/uploads/2018/10/lnFOHB-134Setembro2018.pdf>. Acesso em: 06 de nov. 2018.

FRAJ, E.; MATUTE, J.; MELERO, I. Environmental strategies and organizational competitiveness in the hotel industry: The role of learning and innovation as determinants of environmental success. Tourism Management, v. 46, p. 30-42, fev. 2015.

HU, Y.; CHEN, K. Predicting hotel review helpfulness: The impact of review visibility, and interaction between hotel stars and review ratings, International Journal of Information Management, v. 36, p. 929-944, 2016.

JLL HOTELS \& HOSPITALITY GROUP. (2017). Hotelaria em números - Brasil 2017. Disponível em:<http://www.jll.com.br/brazil/pt-br/relatorios/175/hotelaria-emnumeros-2017>. Acesso em: 05 de nov. 2018.

KLUYVER, C.; PEARCE II, J. Estratégia: uma visão executiva. 3. Ed. São Paulo: Pearson Prentice Hall, 2010.

MAHONEY, J.; PANDIAN J. R. The resource-based view within the conversation of strategic management. Strategic Management Journal, v. 13, n. 5, p. 363-380, 1992.

NGUYEN, K. A.; COUDOUNARIS, D. N. The mechanism of online review management: a qualitative study. Tourism Management Perspectives, v.16, p. 163175, 2015.

PENROSE, E. T. The Theory of the Growth of the Firm. New York: John Wiley, 1959.

PETERAF, M. The cornerstones of competitive advantage: a resource-based view. Strategic Management Journal, v. 14, n. 3, p.179-192, 1993.

QU, H.; RYAN, B.; CHU, R. The importance of hotel attributes in contributing to travelers' satisfaction in the Hong Kong hotel industry. Journal of Quality Assurance in Hospitality \& Tourism, v. 1, n. 3, p. 65-83, 2000.

REN, L.; QIU, H.; WANG, P.; LIN, P. Exploring customer experience with budget hotels: Dimensionality and satisfaction. International Journal of Hospitality Management, v. 52, p. 13-23, 2016.

RHEE, H.; YANG, S. Does hotel attribute importance differ by hotel? Focusing on hotel star-classifications and customers' overall ratings. Computers in Human Behavior, v. 50, p. 576-587, 2015. 
SHANKA, T.; TAYLOR, R. An investigation into the perceived importance of service and facility attributes to hotel satisfaction. Journal of Quality Assurance in Hospitality \& Tourism, v. 4, n. 3-4, p.119-134, 2004.

SINGH, J.; NARAYAN, A.; MANTHA, M. Word of Mouth - A Powerful Marketing Strategy. International Journal of Advance Research and Development, v. 3, n. 2, 2018.

SIRMON, D.; HITT, M.; IRELAND, R. D. Managing firm resources in dynamic environments to create value: Looking inside the black box. The Academy of Management Review, v. 32, n. 1, p. 273-292, 2007.

SMITH, S.; WHEELER, J. Managing the Customer Experience: Turning Customers into Advocates. Harlow: FT Prentice Hall, 2002.

SPARKS, B. A.; KAM, K.; SO, F.; BRADLEY, G. L. Responding to negative online reviews: The effects of hotel responses on customer inferences of trust and concern. Tourism Management, v. 53, p. 74-85, 2016.

TAVITIYAMANA, P.; QU, H.; ZHANG, H. The impact of industry force factors on resource competitive strategies and hotel performance. International Journal of Hospitality Management, v. 30, n. 3, p. 648-657, 2011.

TUOMINEN, P. The Influence of Trip Advisor Consumer-generated Travel Reviews on Hotel Performance. 2011. Disponível em: < https://uhra.herts.ac.uk/handle/2299/7612>. Acesso em: 20 mar. 2019.

WINE, F.; HAFEEZ, M. Do Strategic Resources Influence SMEs Performance?

Pakistan Journal of Social Sciences, v. 39, n. 3, p. 995-1008, 2019.

ZHANG, Y.; VÁSQUEZ, C. Hotels' responses to online reviews: Managing consumer dissatisfaction. Discourse, Context and Media, v. 6, p. 54-64, 2014.

ZHANG, Y., YANG, Q. Assessing hotel decision-making of disabled guests: satisfaction correlation study between online comments' credibility and perceived risk. Electronic Commerce Research, 2019. 